
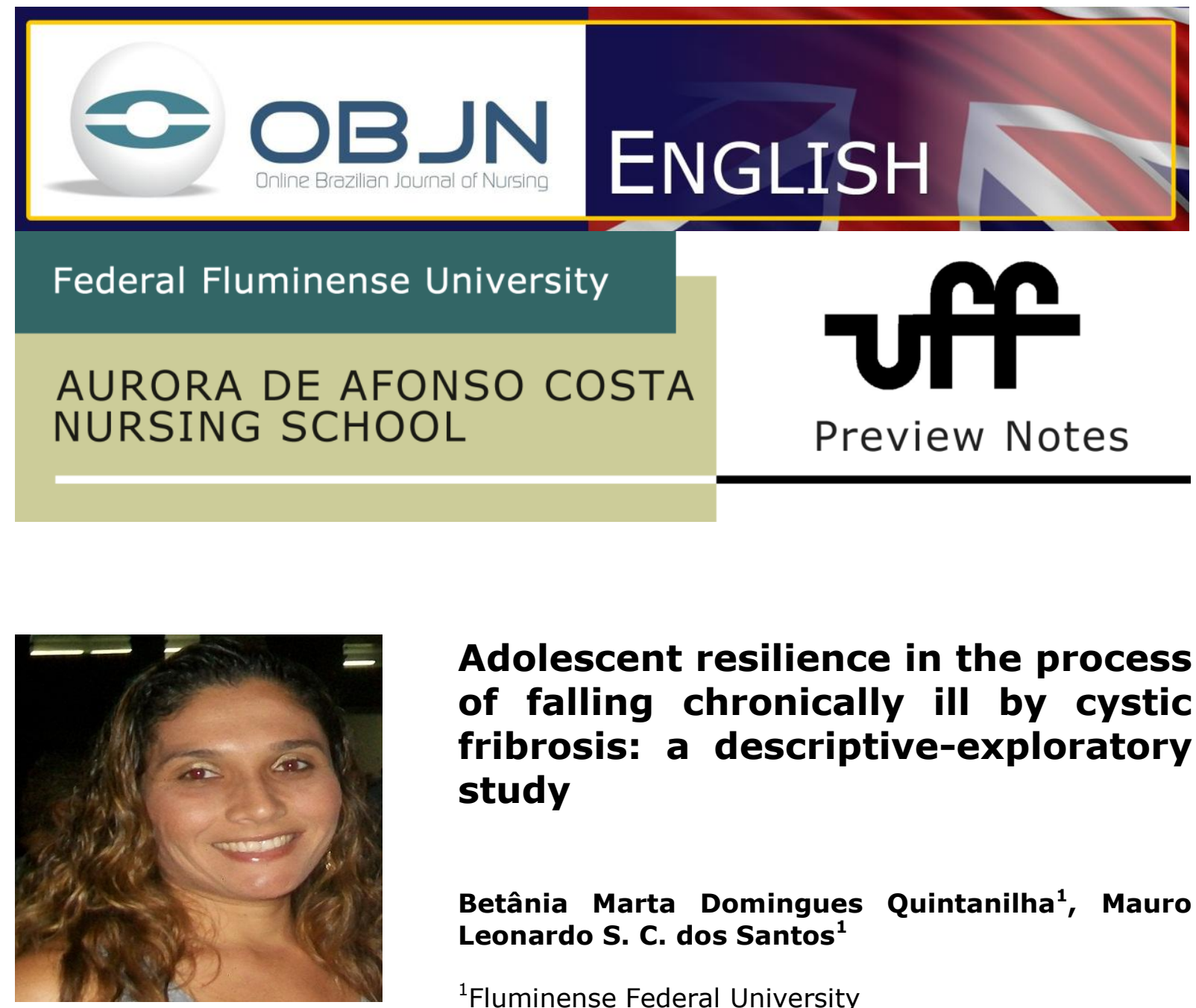

\title{
Adolescent resilience in the process of falling chronically ill by cystic fribrosis: a descriptive-exploratory study
}

\author{
Betânia Marta Domingues Quintanilha', Mauro \\ Leonardo S. C. dos Santos ${ }^{1}$
}

${ }^{1}$ Fluminense Federal University

\begin{abstract}
This study is related to the Professional Master in the Assistant Nursing Program of the Fluminense Federal University. It deals with the resilience in adolescents who are carriers of cystic fibrosis. Objectives: Analyze the process of resilience on the part of adolescent carriers of cystic fibrosis in terms of its risk and protection factors; identify the strategies used by the adolescents with regard to the protection and promotion of his/her quality of life in terms of the risk factors; describe the affected domains which impact on the quality of life; discuss these domains, their relationship with healthcare, and to prepare a handbook for use by such patients. Method: This is a descriptiveexploratory study, performed in a federal hospital in the municipality of Rio de Janeiro, at reference center for the treatment of genetic diseases, including cystic fibrosis. Adolescents between the ages of 12 and 18 diagnosed with cystic fibrosis who have been hospitalized for treatment will participate in this study.
\end{abstract}

Keywords: Resilience Psychological; Adolescent, Cystic Fibrosis; Nursing. 


\section{SITUATION PROBLEM AND ITS SIGNIFICANCE}

Cystic fibrosis (CF) is a chronic, progressive and commonly fatal disease. Some time ago, it was uncommon for those who contracted this disease to live beyond childhood. However, the progress in the treatment of this disease has changed this scenario, increasing life expectancy among the holders of CF. This can be observed by the rise in the number of adolescents, youngsters and even adults living with this illness ${ }^{(1)}$. On the other hand, the dependency on sophisticated treatment programs generates an obstacle to the psychological development of the bearers of this sickness, especially during adolescence. When we refer to adolescent holders of a chronic disease, they face a very delicate situation, because, once it is diagnosed as a chronic disease, all possible phenotypic differences become more remarkable and painful, influencing self-esteem and generating insecurity, and the treatment can cause some interference in the normal growth process $^{(2)}$. The conjuncture of adolescence is multifaceted. There are many aspects of adolescence, influenced by the different processes of development and formation, such as the social-cultural environment, creeds and habits ${ }^{(3)}$. Based on this feature, we decided to study the resilience of adolescents in terms of the process of falling chronically ill due to cystic fibrosis. In this way we can call attention to a collective responsibility for all to identify the resilient factors of the assisted clientele, and collaborate in the adhesion to healthcare plans, aiding the adolescent to face the adverse situation and to allow for the promotion of the quality of life as part of a collective and multidisciplinary task.

\section{GUIDING QUESTIONS}

What are the risks and protection factors that adolescents experience in the process of falling ill due to cystic fibrosis?

What are the strategies used by the adolescents in terms of their protection and the promotion of their quality of life?

Quintanilha BMD, Santos MLSC. Adolescent resilience in the process of falling chronically ill by cystic fribrosis: a descriptive-exploratory study. Online braz j nurs [periodic online]. 2012 Oct [cited year mouth day]; 11 Suppl 1:440-3. Available from: http://www.objnursing.uff.br/index.php/nursing/article/view/3735 
Which domains are affected in terms of the impact on the quality of life of adolescents with cystic fibrosis?

\section{OBJECTIVES}

\section{General:}

Analyze the process of the development of resilience on the part of adolescents in terms of risk and protection factors.

\section{Specific:}

Identify strategies used by adolescents in terms of his own protection and the promotion of the quality of life in terms of the risk factors.

Describe the affected domains which impact on the quality of life, and discuss these domains based on general medical proceedings.

Create a guidebook aimed at aiding the medical proceedings associated with the care of such adolescents.

\section{METHOD}

This is an exploratory-descriptive study, using a qualitative approach, aimed at analyzing the resilience of adolescents in the process of falling chronically ill due to cystic fibrosis. The study will be performed in a tertiary federal hospital in the municipality of Rio de Janeiro. This hospital is a center of reference for genetic diseases, including cystic fibrosis. The criteria for the inclusion of the studied subjects will be: adolescents between 12 and 18 years inclusive, who are diagnosed with cystic fibrosis and in ambulatory treatment for check-up and hospitalization of co-morbidities. The criteria for exclusion are: adolescents above 18 years of age; without legal companionship; in experimental treatment for cystic fibrosis; who were not able to communicate verbally; who are in the final stage of the disease. The collection of data will be through a questionnaire and interviews using two collection instruments: the WHOQOL-BREF, developed by the World Health Organization wich is composed of 26 questions divided into four domains: 
physical, psychological, social relations and environment; and a semi-structured interview about the process of falling ill due to cystic fibrosis, and the strategies used by the respondents towards the protection and the promotion of his quality of life. After the collection of the data, the analysis of the interviews by the researchers will ensue, leading to the exploration and the description of the data through the thematic investigation of the content. The questionnaire scoring will be performed using the statistical software SPSS 13. This study was approved by the Ethics in Research Committee of the College Hospital Antônio Pedro, under registry number $292 \backslash 2011$.

\section{REFERENCES}

1. Pizzignacco TMP, Lima RAG. O processo de socialização de crianças e adolescentes com fibrose cística: subsídios para o cuidado de enfermagem. Rev Latino-am Enfermagem 2006; [cited 2011 may 10]; 14(04): 569-77. Available from: http://www.scielo.br/pdf/rlae/v14n4/pt v14n4a15.pdf

2. Saito MI, Silva LEV. Adolescência - prevenção e risco. São Paulo: Atheneu; 2001.

3. Torres C, Barbosa S, Barroso M, Pinheiro P. Investigating the vulnerability and the risks of adolescents in the midst of STD/ HIV/ Aids in their several contexts - a exploratory study. Online braz j nurs [serial on the Internet]. 2008; [Cited $2011 \mathrm{Dec}$ 6]; 7(1). Available from: http://www.objnursing.uff.br/index.php/nursing/article/view/1138

\section{Project Data}

Project of Master Dissertation of the Post-Graduate in Nursing Program at the Fluminense Federal University, approved in November $24^{\text {th }} 2011$.

CEP approval in 12/12/2011. Registry 292/ 2011.

Financial Support: Regional Council of Nursing (COREN, in Portuguese)

Address for correspondence: Rua Pastor Benedito Borges 12, Alto da Boa Vista, Araruama, RJ, BRAZIL. ZIP 28970-000

\section{Approved: $19 / 01 / 2012$ Received: 03/09/2012}

